\title{
Article \\ Differential Scanning Calorimetry as a New Method to Evaluate the Effectiveness of Rejuvenating Agents in Bitumens
}

\author{
Paolino Caputo *(D) and Cesare Oliviero Rossi \\ Department of Chemistry and Chemical Technologies, UdR INSTM della Calabria, University of Calabria, \\ Via P. Bucci, Cubo 14D, 87036 Rende, Italy; cesare.oliviero@unical.it \\ * Correspondence: paolino.caputo@unical.it
}

Citation: Caputo, P.;

Oliviero Rossi, C. Differential

Scanning Calorimetry as a New Method to Evaluate the Effectiveness of Rejuvenating Agents in Bitumens. Appl. Sci. 2021, 11, 6528. https:// doi.org/10.3390/app11146528

Academic Editor: Anming Hu

Received: 21 June 2021

Accepted: 13 July 2021

Published: 15 July 2021

Publisher's Note: MDPI stays neutral with regard to jurisdictional claims in published maps and institutional affiliations.

Copyright: (c) 2021 by the authors. Licensee MDPI, Basel, Switzerland. This article is an open access article distributed under the terms and conditions of the Creative Commons Attribution (CC BY) license (https:// creativecommons.org/licenses/by/ $4.0 /)$

\begin{abstract}
To date, few methods allow distinguishing a fluxing effect of an additive for bitumen from a regenerating effect. This research aims at identifying a method to accurately establish whether an oxidized bitumen has been regenerated or has simply been fluxed by a softener. Oxidized bitumens, simulating the aging process that results in road pavement lifetime, were prepared by the Rolling thin film oven test (RTFOT) procedure for $225 \mathrm{~min}$ and the Pressure Aging Vessel (PAV) procedure. Their asphaltene parts were extracted and analyzed by calorimetry (Differential Scanning Calorimetry DSC), and the results were compared with the presence and absence of a fluxing agent and real rejuvenators. The self-consistent results showed that the thermal properties of the asphaltene fractions is a sound probe to monitor the effect of rejuvenation clearly distinguishable from the mere fluxing effect. This preliminary study might allow the creation of standard protocols capable of identifying a priori the rejuvenating effect of an additive in the future. Furthermore, given the widespread use of calorimetry for the characterization, it tends to become a widely accessible and useful tool for this purpose in material characterization laboratories.
\end{abstract}

Keywords: bitumen; rejuvenator; fluxing agent; differential canning calorimetry (DSC); light optical microscope; asphaltene

\section{Introduction}

The use of Reclaimed asphalt pavement (RAP) for the production of new road pavements is at the center of research in the bituminous conglomerates sector [1-7]. The use of chemical additives is intended to increase the percentage of RAP in the production of bituminous conglomerates. However, through this strategy, both the performance and the life span of the road is mainly unchanged [8-11]. The most common problem faced by technicians who carry out quality control on bituminous conglomerates and researchers looking for new rejuvenating additives for bitumen is the capability to distinguish the fluxing effect from the rejuvenating effect that the various additives available on the market might possess [12-14]. Indeed, when a mere softening agent is added to a bituminous mixture that in part contains RAP, its overall viscosity will be lowered, thus improving workability. However, in this case, even if the laying of the road pavement can be done without problems, the pavement will be fragile and its lifespan will be shortened, owing to the presence of the oxidized parts of the bitumen coming from the RAP constituent. Identical rheological effect will be obtained using a regenerative agent, but in this specific case, both resistance and lifespan will be on the increase. Indeed, contrary to a mere fluxing agent, a rejuvenating additive will chemically interact with the oxidized parts of the bitumen, bringing their physico-chemical characteristics back to their initial state before the oxidation phenomena [15-17]. This restores elasticity to the bitumen binder besides simply lowering its viscosity. For this reason, it is therefore highly important to be able to distinguish, for a given unknown bituminous mixture, which of these additives, i.e., fluxing agent vs. regenerative agent, has indeed been employed. To face this problem, some considerations are useful: literature studies have shown that during the oxidation 
phenomenon, the clusters of asphaltene molecules that make up the solid part of the bitumen tend to increase their size, stiffening the system [18-21]. This phenomenon was mainly observed by atomic force microscopy (AFM) and scanning electron microscope (SEM) analyses [22-25]. Asphaltenes are compounds with high molecular weights present, in bitumen typically in $5 \%$ to $30 \%$ by weight, and are insoluble in $n$-pentane, and therefore they can be isolated from the rest of the bitumen by simple precipitation [26]. It has been observed that their percentage in bitumen increases to the detriment of the maltene part after oxidation.

In this study, to simulate the aging process occurring during the lifespan of road pavements, 2 methods were used: Rolling Thin Film Oven Test (RTFOT) $[27,28]$ and Pressure Aging Vessel (PAV) [29-31]. These 2 types of aging processes were chosen as they are the most commonly used in research in this field. Furthermore, PAV is the methodology used in the UNI EN 14769 Regulation for simulating the aging of road bitumens. Four different recycling agents (either softening or rejuvenating agents) were mixed to two different types of bitumen. In each case, the asphaltene fractions were extracted and analyzed by Differential Scanning Calorimetry (DSC) [32-34], a routinely used method for the characterization of the thermal properties of materials. DSC is a technique that enables the characterization of several physico-chemical characteristics of materials. It is used to evaluate and determine phenomena such as crystallization, melting, characterization of glass transition, mesomorphic transition temperatures and the corresponding enthalpy and entropy changes. It is also used to characterize and quantify other effects that evidence changes in latent heat or heat capacity. A major advantage of this technique is its simplicity and ability to be applied over a diverse range of samples (solids, gels and even powder form). This analytical technique is an effective tool for characterizing the physical properties of resins, polymers, waxes, etc. It is a somewhat universal method that does not entail very sophisticated technical know-how due to its relative simplicity in comparison to several other techniques. In addition to this, the energy characteristics (heat capacity $\mathrm{C} \mathrm{P}$ and its integral over temperature $\mathrm{T}$-enthalpy $\mathrm{H}$ ), which are measured via calorimetry, have a clear relatable physical meaning [35-40]. The aforementioned materials, i.e., polymers, waxes and resins, are mostly used in the road-paving sector, and from this it can be implied that the DSC technique is already known in this sector and therefore applying it also for the evaluation of the regenerating effect will be advantageous and simple. Through this study, we demonstrated how to effectively distinguish a real rejuvenating effect from a mere fluxing one. This discovery will push the use of common and cheap methods allowing, in the future, the setting up of standard protocols to identify a priori the rejuvenating effect of an additive from a mere fluxing influence.

\section{Experimental}

\subsection{Materials and Reagents}

For this study, we chose two types of bitumen, both with penetration grade 50/70 (Type 1 and Type 2). As for the recycling agent, 4 different recycling agents from both vegetable and mineral sources (TPI, Soy Oil, Agent 3 and Agent 4) were selected: Soy Oil and Agent 4 are known to have a softening effect, whereas TPI and Agent 3 are known for possessing a rejuvenating effect.

The two bitumens and the four additives have already been used in research studies with the aim of evaluating their rejuvenating and/or fluxing effect. Interested readers are referred to the relative publications for details about the preparation, dosage samples and induced change in the rheological properties of the bitumens [41,42]. However, useful information about Type 1-2 bitumens and the four recycling agents are summarized in Tables 1 and 2. 
Table 1. Information about the bitumens.

\begin{tabular}{cccccc}
\hline & Label & $\begin{array}{c}\text { Penetration Grade } \\
\mathbf{( 0 . 1} \mathbf{~ m m}) \pm \mathbf{1}\end{array}$ & $\begin{array}{c}\text { Softening Point } \\
\left({ }^{\circ} \mathbf{C}\right) \pm \mathbf{0 . 2}\end{array}$ & $\begin{array}{c}\text { Asphaltene } \\
\text { No Age (\%) }\end{array}$ & $\begin{array}{c}\text { Asphaltene } \\
\text { after Aging } \mathbf{~ ( \% )}\end{array}$ \\
\hline Bitumen 50/70 & Type 1 & 68 & 48.8 & 26.8 & 34.2 \\
Bitumen 50/70 & Type 2 & 63 & 55.0 & 30.9 & 36.9 \\
\hline
\end{tabular}

Table 2. Information about the additives.

\begin{tabular}{lcccc}
\hline & Label & Type of Additive & Effect & Dosage (\%) \\
\hline Recycling agent 1 & TPI & Poly Phosphate & Regenerator & 4 \\
Recycling agent 2 & Soy oil & Vegetable Oil & Softener & 4 \\
Recycling agent 3 & Agent 3 & Vegetable Oil + other components & Regenerator & 6 \\
Recycling agent 4 & Agent 4 & Mineral & Softener & 6 \\
\hline
\end{tabular}

We observed (Table 1) that for both types of bitumen the \% asphaltene increases after the aging process. In this study, Type 1 bitumen was artificially aged by means of the Rolling Thin Film Oven Test (RTFOT by 81-PV1612 Controls, Liscate, Italy) according to the ASTM D1754 standard, which stipulates a thermal treatment of $75 \mathrm{~min}$ at $163{ }^{\circ} \mathrm{C}$, and also by using a variation of this standard (i.e., thermal treatment of $225 \mathrm{~min}$ at $163{ }^{\circ} \mathrm{C}$ ). On the other hand, Type 2 bitumen was aged by Pressure Aging Vessel (PAV by Prentex PAV-Alloy fabricators Inc., Model 9300-Dallas, TX-USA) according to the UNI EN 14769. For all tested mixtures, the asphaltene content was isolated from the rest of the bitumen mixture by simple precipitation following the previously reported procedure [43].

\subsection{Differential Scanning Calorimetry (DSC)}

The calorimetric behavior of the asphaltene samples was analyzed using a DSC SETARAM 131 instrument.

Before starting the tests on the instrument, the calibration operations were carried out using a sample of Indium with a known weight. In fact, knowing exactly the values relating to the enthalpy $(\Delta \mathrm{H})$ of the melts and the exact position of the sample of Indium, it was possible to calibrate the instrument. Then, $20-30 \mathrm{mg}$ of each sample was weighed in a crucible and subsequently, the container was capped and sealed by mechanical press. From a screening carried out, it was determined that the amount of sample does not affect the trend of the calorimetric curve, but acts only on the intensity of the signals. All the tests were carried out under nitrogen flow.

Following method was used to analyze all samples:

1. Isotherm at $25^{\circ} \mathrm{C}$ for $20 \mathrm{~min}$;

2. Heating from $25^{\circ} \mathrm{C}$ to $250{ }^{\circ} \mathrm{C}$ at $20^{\circ} \mathrm{C} \mathrm{min}{ }^{-1}$;

3. Cooling from $250{ }^{\circ} \mathrm{C}$ to $25^{\circ} \mathrm{C}$ at $20^{\circ} \mathrm{C} \mathrm{min}^{-1}$;

4. Isotherm at $25^{\circ} \mathrm{C}$ for $20 \mathrm{~min}$;

5. Heating from $25^{\circ} \mathrm{C}$ to $250{ }^{\circ} \mathrm{C}$ at $20^{\circ} \mathrm{C} \mathrm{min}-1$

Note that the first heating and cooling cycle was effectuated to ensure identical thermal history for all samples. Indeed, during the first thermal ramp, various endothermal or exothermal peaks could be observed according to the exact starting state of the sample, which is hardly controlled through a precipitation process. After a first heating, a cooling ramp of all samples at the same controlled scan rate ensures that all samples are placed

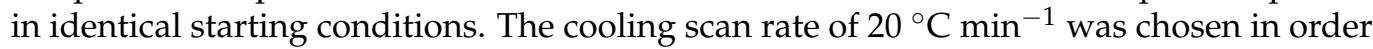
to maximize the probability of freezing the asphaltene samples in their amorphous state. For this reason, DSC traces obtained from the second heating ramp only displayed glass temperature (Tg) transitions that can be easily compared between the samples and thus correlate to the nature of the sample. Consequently, in this work, only the calorimetric curves derived from the second thermal ramp will be shown, described and analyzed. As reported 
in literature by thermogravimetric analysis (TGA) measurements at the temperature of $250{ }^{\circ} \mathrm{C}$, the asphaltenes do not show any thermal degradation phenomena [44-46].

\subsection{Light Microscopy}

Samples were examined with a Leica DMLP polarizing microscope equipped with a Leica DFC280 camera and a CalCTec (Leica Microsystems Srl, Buccinasco (MI)-Italy) heating stage.

The samples were inserted in a double microscope glass slide (sandwich model), and a temperature ramp was carried out with a starting temperature of $120^{\circ} \mathrm{C}$ and a heating rate of $5{ }^{\circ} \mathrm{C}$ per minute. After every $5{ }^{\circ} \mathrm{C}$ increase, samples were left to stay for $1-2 \mathrm{~min}$ to ensure uniformity and homogenous heating through all the samples, and photos were taken.

\section{Results and Discussion}

\subsection{Differential Scanning Calorimetry (DSC)}

The present study was performed to check whether asphaltenes contained in bitumen could represent a probe to identify whether a recycled bitumen mixture has been rejuvenated or only fluxed by a softener agent. This hypothesis was based on the fact that upon oxidation of bitumen, the clusters of asphaltene molecules that contribute to the solid part of the bitumen tend to increase in size, thus stiffening the system [20-23]. Asphaltenes are compounds with high molecular weights present in bitumens generally in $5 \%$ to $30 \%$ by weight and are insoluble in $n$-pentane, so that they can be isolated from the rest of bitumen by simple precipitation [43]. It has been furthermore observed that upon oxidation, their percentage in bitumen increases to the detriment of the maltene part. For these reasons, it seemed reasonable to forecast that the thermal properties of asphaltenes could be correlated to the historical background of bitumen. Indeed, if rejuvenation occurred, the asphaltenes may also have their initial thermal behavior restored.

In Figure 1, the calorimetric analysis of all the samples obtained with both the bitumens utilized in this study are reported.

Figure 1a shows the trend of the calorimetric curves relative to the asphaltene samples derived from the aged-by-RTFOT and non-aged Type 1 bitumen. RTFOT was carried out for $75 \mathrm{~min}$ in accordance to the standard procedure ASTM D2872-04 and for $225 \mathrm{~min}$ to obtain a bitumen (identified in the present work as "RTFOT-225 min") rigid enough to simulate a prolonged ageing process of 10-12 years, which is a period typical of recycled asphalts [47]. In all the samples, we found the presence of inflection points typical of glass transition [48-51] (indicated in the graph segment enclosed between the two-colored vertical bars). The TG temperature of a material characterizes the temperature range over which this glass transition occurs. Firstly, it was observed that increasing the oxidation time, the inflection point moves towards higher temperatures. The same effect was observed for the first signal of the calorimetric curve (indicated in the graph with the $\mathrm{X}$ symbol). In particular, in the case of bitumen aged for $75 \mathrm{~min}$, one remaining peak is also observed between the first signal of the calorimetric curve and the glass transition (indicated in the graph with a red arrow). This is because prior knowledge from scientific literature on this topic makes us understand that the asphaltenes form aggregated clusters [52-56]. Some of these aggregated forms of clusters involve weaker interactions with a looser, longer range and self-assembly, and so are more exposed to oxidation, while those clusters in which the asphaltene molecules form a stuck structure (more tightly packed) are not as easily oxidized due to their compact structure.

The addition of the regenerating additive TPI (green line) brings back the inflection point (in the figure represented by the segment enclosed between 2 beads on the curve) to values similar to those obtained for pristine bitumen while the addition of the fluxing additive commonly known as Soy Oil (purple line) shows a TG very similar to that observed for the bitumen aged by using RTFOT for $225 \mathrm{~min}$. 

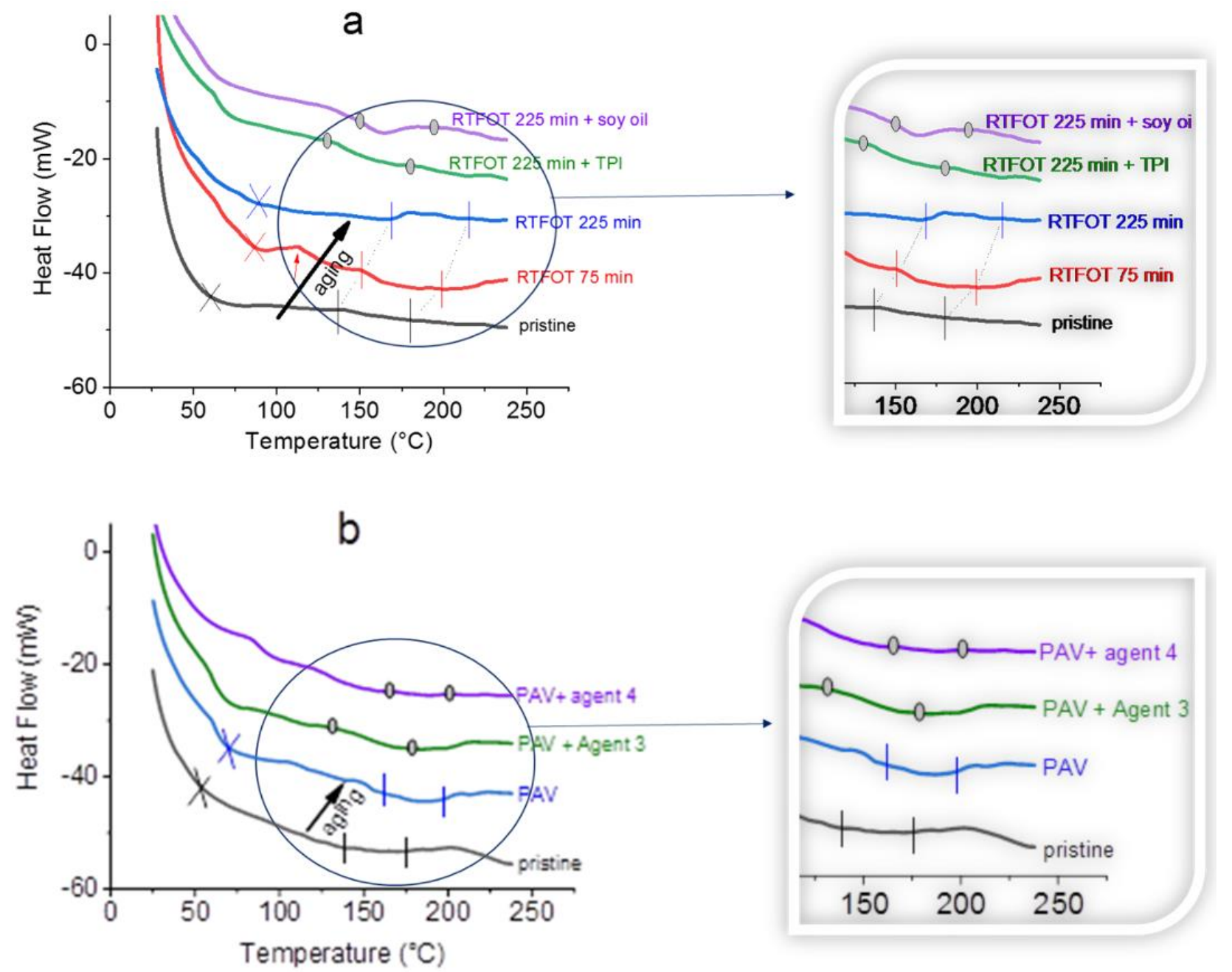

Figure 1. (a) DSC of asphaltenes bitumen Type 1 Non-Aged, RTFOT 75 and 225 min, showing the effect of aging, as compared to the RTFOT 225 after addition of TPI and Soy Oil; (b) DSC of asphaltenes bitumen Type 2 Non-Aged and PAV aged, as compared to the PAV aged after addition of Agent 3 and 4.

The chemical basis of their different effect has been clarified: the Soy Oil, due to its mostly apolar structure, is expected to be localized in the maltenic fraction, probably establishing basically apolar interactions. TPI, on the other hand, thanks to its phosphate group, can bind asphaltene clusters. The possibility of organophosphate to establish strong interactions was recently pointed out [57].

Parallel to this, the apolar molecular moiety renders TPI truly amphiphilic, the effect of which can be in synergy with the resins naturally present in the bitumens: If different amphiphiles are close together, they can give rise to peculiar self-assembly [58] with unexpected emerging properties and dynamics [59] up to the formation of ionic liquids [60,61]. Therefore, the peculiar effect of TPI can be traced back not only to its peculiar structure, but also to the combined action with the other stabilizing amphiphiles naturally present in the bitumens.

Looking at the trend of the calorimetric curve of the asphaltenes derived from TPIregenerated bitumen, it results as an intermediate between the one obtained for pristine bitumen and that obtained after aging with RTFOT for $75 \mathrm{~min}$. In fact, it is noted that the RTFOT aging process for $75 \mathrm{~min}$ simulates the mixing process of the conglomerate and so reproduces a binder with the real chemico-physical characteristics of those present in the road pavement after having been put to use. Therefore, through these calorimetric measurements, it was possible to distinguish between the regenerating effect from the fluxing effect. 
In Figure $1 b$, the calorimetric curves are reported for the asphaltenes obtained from the second type of bitumen (Type 2) used in this study, which was aged by PAV. In this case we also observed changes in the DSC line in accordance with those obtained for the first type of bitumen: the inflection point positions are influenced by the level of oxidation of the bitumen. In fact, the more oxidized the bitumen is, the more these inflection points are positioned towards higher temperatures. The same effect holds for the first signal of the calorimetric curves, where the characteristic marks of the bitumen aged by PAV occur at higher temperatures compared to those observed for the non-aged bitumen. In addition, with this type of bitumen it can be confirmed that the use of a regenerating additive, and specifically Agent 3 (green line), brings back the TG values of the PAV-aged bitumen to those obtained for non-aged bitumen. On the other hand, an additive without a regenerating capacity but simply with fluxing characteristics such as Agent 4 (purple line) leaves the TG values just as they were.

For both types of bitumen, we can observe that the calorimetric curves obtained for the non-aged bitumen are very linear and they show almost exclusively the inflection points of the material. On the other hand, the calorimetric curves derived from the aged samples (RTFOT or PAV) are more undulating and they present, in addition to the inflection point, other small peaks that are most probably due to the presence of molecules with different melting points inside the sample.

\subsection{Light Microscopy of Asphaltenes}

We used light microscopy to determine the melting points [62-65] of all samples analyzed in this study.

From the microscopy analysis, the results obtained from the DSC measurements are confirmed: microphotographs are reported in Figure 2, and the initial and final temperature values of the solid-liquid transition are reported in Table 3. In fact, while the non-aged bitumen shows a well-defined solid-liquid transition taking place in a short temperature interval, the oxidized bitumen (PAV) shows a gradual melting of the sample taking place in a wider temperature range that begins around $160^{\circ} \mathrm{C}$ and finishes at $175^{\circ} \mathrm{C}$. This justifies the presence of more peaks for the calorimetric curve obtained for the aged sample in addition to the inflection point (TG), while in the case of the non-aged bitumen sample just one common inflection point can be observed. In the case of the asphaltenes coming from the PAV bitumen treated with Agents 3 and 4, self-consistent results are obtained: Agent 3 brings the inflection points back to values similar to those for the non-aged bitumen, whereas Agent 4 brings back the inflection points to values similar to those of PAV-aged bitumen. We intend to highlight the fact that the sample treated with Agent 3 , having a higher transition temperature range compared to the non-aged sample, shows a calorimetric curve with a more complex pattern and presenting more peaks, keeping anyway the same temperature range as for the non-aged bitumen. The different behavior of the melting points of the various asphaltene samples is due both to the different aggregation between them and to their different chemical composition. In fact, when a bitumen is exposed to an aging process, it tends to incorporate oxygen, forming epoxy and sulfoxide bonds and also significantly reducing the aromatic component [41]. This leads to the formation of larger clusters that consequently will tend to melt at higher temperatures. When an additive with a fluxing effect (such as Soy Oil or Agent 4) is added to the aged bitumen, since the latter only has a physical interaction with the bitumen, there is no variation either in the chemical composition or in the size of the clusters, and therefore the melting points remain very similar to aged bitumen. On the other hand, when an additive with a regenerating effect (such as TPI or Agent 3) is added, it chemically interacts with the asphaltenic part of the bitumen, reducing the size of the clusters and above all giving the asphaltene sample a chemical composition very similar to that of non-aged bitumen, restoring the aromatic component and reducing the oxidized parts [41]. Consequently, the melting point values of asphaltenes are very similar to those recorded for non-aged 
bitumen. The melting points for the RTFOT samples of the bitumen Type 1 are also in line with the scenarios reported above [41].
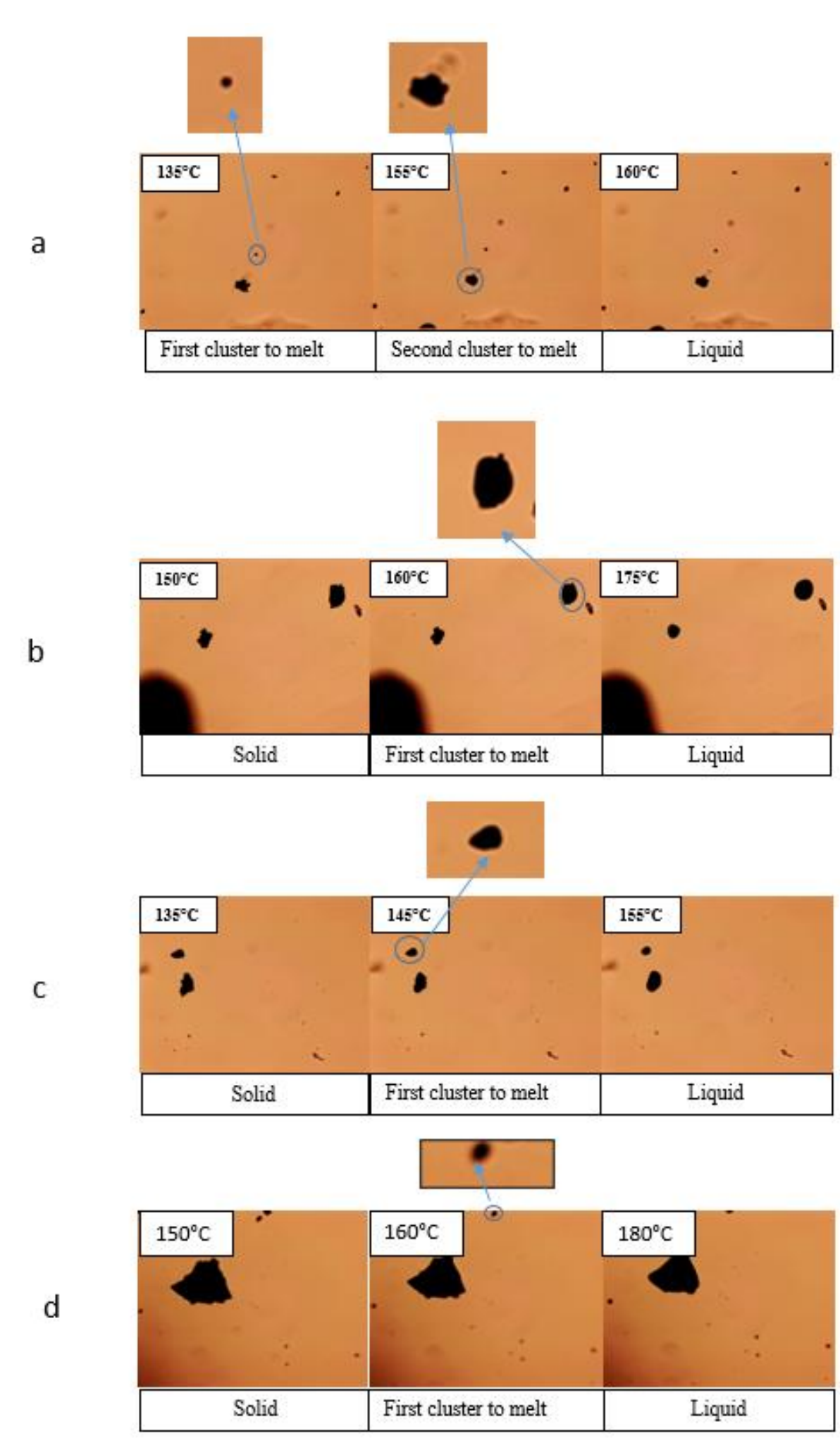

Figure 2. (a) Melting points of asphaltenes of non-aged bitumen; (b) Melting points of PAV; (c) Melting points of PAV + Agent 3; (d) Melting points of PAV + Agent 4. 
Table 3. Melting point of the aged and non-aged samples.

\begin{tabular}{cccc}
\hline Figure & Sample (Type 2 Bitumen) & Initial Melting $\left({ }^{\circ} \mathbf{C}\right)$ & Final Melting Point $\left({ }^{\circ} \mathbf{C}\right)$ \\
\hline Figure 2a & Bit. No Aged & 145 & 160 \\
Figure 2b & PAV & 160 & 175 \\
Figure 2c & PAV Agent 3 & 135 & 155 \\
Figure 2d & PAV Flux Agent 4 & 170 & 180 \\
\hline
\end{tabular}

\section{Conclusions}

Differential Scanning Calorimetry (DSC) via this study proved to be a well-established technique to differentiate between a simple fluxing agent and a real rejuvenating agent. From the results obtained in this study, we were able to prove that DSC is a useful method and an effective method for the aforementioned purpose, most especially because compared to other methods and techniques with the same objective, it is relatively cost-effective and easy to carry out.

This is because it is a technique that involves methodology and instrumentation already present in most laboratories that deal with characterization of materials and therefore there is no need for the procurement of new reagents and external personnel with technical know-how to carry out a novel technique. This will facilitate the diffusion and widespread use of the method in laboratories and agencies such as ANAS, NAPA, NCAT, etc., which are involved in the quality control of asphalt mixes. It will also enable these agencies to include additional information as regards bitumen aging and rejuvenation without the need for investing new resources to achieve this end. This already existing yet innovative technique will in the future enable the use of this common method for the design of standard protocols in order to categorically distinguish a priori an ordinary fluxing influence from a rejuvenating effect of an additive.

Author Contributions: Methodology, C.O.R.; formal analysis, C.O.R.; investigation, P.C.; data curation, C.O.R. and P.C.; writing-original draft, P.C.; writing-review \& editing C.O.R.; supervision, C.O.R. All authors have read and agreed to the published version of the manuscript.

Funding: This research received no external funding.

Institutional Review Board Statement: Not applicable.

Informed Consent Statement: Not applicable.

Data Availability Statement: The data presented in this study are available on request from the corresponding authors.

Conflicts of Interest: The authors declare no conflict of interest.

\section{References}

1. Yousefi, A.; Behnood, A.; Nowruzi, A.; Haghshenas, H. Performance evaluation of asphalt mixtures containing warm mix asphalt (WMA) additives and reclaimed asphalt pavement (RAP). Constr. Build. Mater. 2021, 268, 121200. [CrossRef]

2. Valdés, G.; Pérez-Jiménez, F.; Miró, R.; Martínez, A.; Botella, R. Experimental study of recycled asphalt mixtures with high percentages of reclaimed asphalt pavement (RAP). Constr. Build. Mater. 2011, 25, 1289-1297. [CrossRef]

3. Muthumala George, A.; Banerjee, A.; Puppala, A.J.; Saladhi, M. Performance evaluation of geocell-reinforced reclaimed asphalt pavement (RAP) bases in flexible pavements. Int. J. Pavement Eng. 2021, 22, 181-191. [CrossRef]

4. Mousa, E.; El-Badawy, S.; Azam, A. Evaluation of reclaimed asphalt pavement as base/subbase material in Egypt. Transp. Geotech. 2021, 26, 100414. [CrossRef]

5. Antunes, V.; Neves, J.; Freire, A.C. Performance Assessment of Reclaimed Asphalt Pavement (RAP) in Road Surface Mixtures. Recycling 2021, 6, 32. [CrossRef]

6. Rafiq, W.; Musarat, M.A.; Altaf, M.; Napiah, M.; Sutanto, M.H.; Alaloul, W.S.; Javed, M.F.; Mosavi, A. Life Cycle Cost Analysis Comparison of Hot Mix Asphalt and Reclaimed Asphalt Pavement: A Case Study. Sustainability 2021, 13, 4411. [CrossRef]

7. Loise, V.; Caputo, P.; Porto, M.; Angelico, R.; Rossi Oliviero, C. A review on Bitumen Rejuvenation: Mechanisms, materials, methods and perspectives. Appl. Sci. 2019, 9, 4316. [CrossRef]

8. Xu, H.; Chen, J.; Sun, Y.; Zhu, X.; Wang, W.; Liu, J. Rheological and physico-chemical properties of warm-mix recycled asphalt mastic containing high percentage of RAP binder. J. Clean. Prod. 2021, 289, 125134. [CrossRef] 
9. Bizarro, D.E.G.; Steinmann, Z.; Nieuwenhuijse, I.; Keijzer, E.; Hauck, M. Potential Carbon Footprint Reduction for Reclaimed Asphalt Pavement Innovations: LCA Methodology, Best Available Technology, and Near-Future Reduction Potential. Sustainability 2021, 13, 1382. [CrossRef]

10. Spreadbury, C.J.; Clavier, K.A.; Lin, A.M.; Townsend, T.G. A critical analysis of leaching and environmental risk assessment for reclaimed asphalt pavement management. Sci. Total Environ. 2021, 775, 145741. [CrossRef]

11. Caputo, P.; Loise, V.; Ashimova, S.; Teltayev, B.; Vaiana, R.; Oliviero Rossi, C. Inverse Laplace Transform (ILT)NMR: A powerful tool to differentiate a real rejuvenator and a softener of aged bitumen. Colloids Surf. A 2019, 574, 154-161. [CrossRef]

12. Mangiafico, S.; Sauzéat, C.; Di Benedetto, H.; Pouget, S.; Olard, F.; Planque, L. Complex modulus and fatigue performances of bituminous mixtures with reclaimed asphalt pavement and a recycling agent of vegetable origin. Road Mater. Pavement Des. 2017, 18, 2315-2330. [CrossRef]

13. Nodari, C.; Crispino, M.; Toraldo, E. Laboratory investigation on the use of recycled materials in bituminous mixtures for dense-graded wearing course. Case Stud. Constr. Mater. 2021, 15, e00556.

14. Grilli, A.; Gnisci, M.I.; Bocci, M. Effect of ageing process on bitumen and rejuvenated bitumen. Constr. Build. Mater. 2017, 136, 474-481. [CrossRef]

15. Huang, W.; Guo, Y.; Zheng, Y.; Ding, Q.; Sun, C.; Yu, J.; Zhu, M.; Yu, H. Chemical and rheological characteristics of rejuvenated bitumen with typical rejuvenators. Constr. Build. Mater. 2021, 273, 121525. [CrossRef]

16. Mazzoni, G.; Bocci, E.; Canestrari, F. Influence of rejuvenators on bitumen ageing in hot recycled asphalt mixtures. J. Traffic Transp. Eng. 2018, 5, 157-168. [CrossRef]

17. Zhang, J.-; Sun, C.; Li, P.; Jiang, H.; Liang, M.; Yao, Z.; Zhang, X.; Airey, G. Effect of different viscous rejuvenators on chemical and mechanical behavior of aged and recovered bitumen from RAP. Constr. Build. Mater. 2020, 239, 117755. [CrossRef]

18. Hesp, S.A.; Iliuta, S.; Shirokoff, J.W. Reversible Aging in Asphalt Binders. Energy Fuels 2007, 21, 1112-1121. [CrossRef]

19. Tauste, R.; Moreno-Navarro, F.; Sol-Sánchez, M.; Rubio-Gámez, M.C. Understanding the bitumen ageing henomenon: A review. Constr. Build. Mater. 2018, 192, 593-609. [CrossRef]

20. Wang, Y.; Zhao, K.; Li, F.; Gao, Q.; Lai, K.W.C. Asphaltenes in asphalt: Direct observation and evaluation of their impacts on asphalt properties. Constr. Build. Mater. 2021, 271, 121862. [CrossRef]

21. Shedid, S.A. An ultrasonic irradiation technique for treatment of asphaltene deposition. J. Pet. Sci. Eng. 2004, 42, 57-70. [CrossRef]

22. Hemmati-Sarapardeh, A.; Dabir, B.; Ahmadi, M.; Mohammadi, A.H.; Husein, M.M. Toward mechanistic understanding of asphaltene aggregation behavior in toluene: The roles of asphaltene structure, aging time, temperature, and ultrasonic radiation. J. Mol. Liq. 2018, 264, 410-424. [CrossRef]

23. Moir, M.E. Asphaltenes, What Art Thou? Asphaltenes and the Boduszynski Continuum. ACS Symp. Ser. 2018, 1282. [CrossRef]

24. Sharipov, T.I.; Yu Dolomatov, M.; Bakhtizin, R.Z. The study of supramolecular structure of asphaltenes by atomic force microscopy. IOP Conf. Ser. Mater. Sci. Eng. 2018, 443, 012028. [CrossRef]

25. Caputo, P.; Porto, M.; Calandra, P.; De Santo, M.P.; Oliviero Rossi, C. Effect of epoxidized soybean oil on mechanical properties of bitumen and aged bitumen. Mol. Cryst. Liq. Cryst. 2018, 675, 68-74. [CrossRef]

26. Caputo, P.; Loise, V.; Crispini, A.; Sangiorgi, C.; Scarpelli, F.; Oliviero Rossi, C. The efficiency of bitumen rejuvenator investigated through Powder X-ray Diffraction (PXRD) analysis and T2-NMR spectroscopy. Colloids Surf. A 2019, 571, 50-54. [CrossRef]

27. Yan, C.; Huang, W.; Tang, N. Evaluation of the temperature effect on Rolling Thin Film Oven aging for polymer modified asphalt. Constr. Build. Mater. 2017, 137, 485-493. [CrossRef]

28. Shalaby, A. Modelling short-term aging of asphalt binders using the rolling thin film oven test. Can. J. Civ. Eng. 2002, 29, 135-144. [CrossRef]

29. Hofko, B.; Hospodka, M. Rolling Thin Film Oven Test and Pressure Aging Vessel Conditioning Parameters: Effect on Viscoelastic Behavior and Binder Performance Grade. Transp. Res. Rec. J. Transp. Res. Board 2016, 2574. [CrossRef]

30. Qiu, X.; Cheng, W.; Xu, W.; Xiao, S.; Yang, Q. Fatigue evolution characteristic and self-healing behaviour of asphalt binders. Int. J. Pavement Eng. 2020, 1-12. [CrossRef]

31. Oliviero Rossi, C.; Caputo, P.; Loise, V.; Ashimova, S.; Teltayev, B.; Sangiorgi, C. A New Green Rejuvenator: Evaluation of Structural Changes of Aged and Recycled Bitumens by Means of Rheology and NMR. In RILEM 252-CMB-Symposium on Chemo Mechanical Characterization of Bituminous Materials; Bookseries 20; Poulikakos, L.D., Ed.; Springer: Cham, Switzerland, 2019; pp. 177-182. [CrossRef]

32. Jiménez-Mateos, J.M.; Quintero, L.C.; Rial, C. Characterization of petroleum bitumens and their fractions by thermogravimetric analysis and differential scanning calorimetry. Fuel 1996, 75, 1691-1700. [CrossRef]

33. Varfolomeev, M.A.; Galukhin, A.; Nurgaliev, D.K.; Kok, M.V. Thermal decomposition of Tatarstan Ashal'cha heavy crude oil and its SARA fractions. Fuel 2016, 186, 122-127. [CrossRef]

34. Kök, M.V.; Gul, K.G. Combustion characteristics and kinetic analysis of Turkish crude oils and their SARA fractions by DSC. J. Anal. Calorim. 2013, 114, 269-275. [CrossRef]

35. Schick, C. Differential scanning calorimetry (DSC) of semicrystalline polymers. Anal. Bioanal. Chem. 2009, 395, 1589. [CrossRef]

36. Windt, M.; Meier, D.; Lehnen, R. Quantification of polypropylene (PP) in wood plastic composites (WPCs) by analytical pyrolysis (Py) and differential scanning calorimetry (DSC). Holzforschung 2011, 65, 199-207. [CrossRef]

37. Park, B.D.; Riedl, B.; Hsu, E.W.; Shields, J. Differential scanning calorimetry of phenol-formaldehyde resins cure- accelerated by carbonates. Polymer 1999, 40, 1689-1699. [CrossRef] 
38. Hay, J.N.; Mills, P.J. The use of differential scanning calorimetry to study polymer crystallization kinetics. Polymer 1982, 23, 1380-1384. [CrossRef]

39. Ruguo, Z.; Hua, Z.; Hong, Z.; Ying, F.; Kun, L.; Wenwen, Z. Thermal Analysis of Four Insect Waxes Based on Differential Scanning Calorimetry (DSC). Procedia Eng. 2011, 18, 101-106. [CrossRef]

40. Flaherty, B. Characterisation of waxes by differential scanning calorimetry. J. Appl. Chem. Biotechnol. 1971, 21, 144-148. [CrossRef]

41. Loise, V.; Calandra, P.; Abe, A.A.; Porto, M.; Oliviero Rossi, C.; Davoli, M.; Caputo, P. Additives on aged bitumens: What probe to distinguish between rejuvenating and fluxing effects? J. Mol. Liq. 2021. [CrossRef]

42. Caputo, P.; Eskandarsefat, S.; Porto, M.; Loise, V.; Oliviero Rossi, C.; Scarpelli, F.; De Santo, M.P.; Venturini, L. Towards advances in differentiating recycling agents: Softening agents vs. rejuvenating agents. In Proceedings of the 7th EE CONGRESS Eurasphalt Eurobitume, Virtual, 15-17 June 2021.

43. Oliviero Rossi, C.; Caputo, P.; De Luca, G.; Maiuolo, L.; Eskandarsefat, S.; Sangiorgi, C. ${ }^{1}$ H-NMR Spectroscopy: A Possible Approach to Advanced Bitumen Characterization for Industrial and Paving Applications. Appl. Sci. 2018, 8, 229. [CrossRef]

44. Hassan Firoozifar, S.; Foroutan, S.; Foroutan, S. The effect of asphaltene on thermal properties of bitumen. Chem. Eng. Res. Des. 2011, 89, 2044-2048. [CrossRef]

45. Prakoso, A.; Punase, A.; Klock, K.; Rogel, E.; Ovalles, C.; Berna, H. Determination of the Stability of Asphaltenes Through Physicochemical Characterization of Asphaltenes. SPE West. Reg. Meet. Anchorage Alsk. USA 2016. [CrossRef]

46. Rogel, E.; Ovalles, C.; Moir, M. Asphaltene Chemical Characterization as a Function of Solubility: Effects on Stability and Aggregation. Energy Fuels 2012, 26, 2655-2662. [CrossRef]

47. Caputo, P.; Calandra, P.; Vaiana, R.; Gallelli, V.; De Filpo, G.; Oliviero Rossi, C. Preparation of Asphalt Concretes by Gyratory Compactor: A Case of Study with Rheological and Mechanical Aspects. Appl. Sci. 2020, 10, 8567. [CrossRef]

48. Hutchinson, J.M. Studying the Glass Transition by DSC and TMDSC. J. Therm. Anal. Calorim. 2003, 72, 619-629. [CrossRef]

49. Donth, E.; Korus, J.; Hempel, E.; Beiner, M. Comparison of DSC heating rate and HCS frequency at the glass transition. Thermochim. Acta 1997, 304-305, 239-249. [CrossRef]

50. Tseretely, G.I.; Smirnova, O.I. DSC study of melting and glass transition in gelatins. J. Therm. Anal. 1992, 38, 1189-1201. [CrossRef]

51. Schawe, J.E.K. Principles for the interpretation of modulated temperature DSC measurements. Part 1. Glass transition. Thermochim. Acta 1995, 261, 183-194. [CrossRef]

52. Calandra, P.; Caputo, P.; De Santo, M.P.; Todaro, L.; Turco Liveri, V.; Oliviero Rossi, C. Effect of additives on the structural organization of asphaltene aggregates in bitumen. Constr. Build. Mater. 2019, 199, 288-297. [CrossRef]

53. Hoepfner, M.P.; Vilas Bôas Fávero, C.; Haji-Akbari, N.; Scott Fogler, H. The Fractal Aggregation of Asphaltenes. Langmuir 2013, 29, 8799-8808. [CrossRef]

54. Headen, T.F.; Boek, E.S.; Jackson, G.; Totton, T.S.; Müller, E.A. Simulation of Asphaltene Aggregation through Molecular Dynamics: Insights and Limitations. Energy Fuels 2017, 31, 1108-1125. [CrossRef]

55. Porto, M.; Caputo, P.; Loise, V.; De Filpo, G.; Oliviero Rossi, C.; Calandra, P. Polysaccharides-Reinforced Bitumens: Specificities and Universality of Rheological Behavior. Appl. Sci. 2019, 9, 5564. [CrossRef]

56. Goual, L.; Sedghi, M.; Zeng, H.; Mostowfi, F.; McFarlane, R.; Mullins, O.C. On the formation and properties of asphaltene nanoaggregates and clusters by DC-conductivity and centrifugation. Fuel 2011, 90, 2480-2490. [CrossRef]

57. Calandra, P.; De Caro, T.; Caschera, D.; Lombardo, D.; Todaro, L.; Liveri, V. Spectroscopic and structural characterization of pure and FeCl3-containing tri-n-butyl phosphate. Colloid Polym. Sci. 2014, 293, 597-603. [CrossRef]

58. Calandra, P.; Ruggirello, A.; Mele, A.; Liveri, V.T. Self-assembly in surfactant-based liquid mixtures: Bis(2-ethylhexyl)phosphoric acid/bis(2-ethylhexyl)amine systems. J. Colloid Interface Sci. 2010, 348, 183-188. [CrossRef]

59. Calandra, P.; Nicotera, I.; Oliviero Rossi, C.; Liveri, V.T. Dynamical properties of self-assembled surfactant-based mixtures: Triggering of one-dimensional anomalous diffusion in bis(2-ethylhexyl)phosphoric acid/n-octylamine systems. Langmuir 2013, 29, 14848-14854. [CrossRef]

60. Turco Liveri, V.; Lombardo, D.; Pochylski, M.; Calandra, P. Molecular association of small amphiphiles: Origin of ionic liquid properties in dibutyl phosphate/propylamine binary mixtures. J. Mol. Liq. 2018, 263, 274-281. [CrossRef]

61. Calandra, P. On the physico-chemical basis of self-nanosegregation giving magnetically-induced birefringence in dibutyl phosphate/bis(2-ethylhexyl) amine systems. J. Mol. Liq. 2020, 310, 113186. [CrossRef]

62. Zhang, Y.; Takanohashi, T.; Sato, S.; Saito, I.; Tanaka, R. Observation of Glass Transition in Asphaltenes. Energy Fuels 2004, 18. [CrossRef]

63. Li, X.; Guo, Y.; Sun, Q.; Lan, W.; Liu, A.; Guo, X. Experimental study for the impacts of flow rate and concentration of asphaltene precipitant on dynamic asphaltene deposition in microcapillary medium. J. Pet Sci. Eng. 2018, 162. [CrossRef]

64. Bearsley, S.; Fobes, A.; Haverkamp, R.G. Direct observation of the asphaltene structure in paving-grade bitumen using confocal laser-scanning microscopy. J. Microsc. 2004, 215. [CrossRef]

65. Lu, X.; Langton, M.; Olofsson, P. Wax morphology in bitumen. J. Mater. Sci. 2005, 40, 1893-1900. [CrossRef] 